\title{
Right ventricular anatomical and functional parameters in healthy Mexican term newborns
}

\author{
Parámetros anatómicos y funcionales del ventrículo derecho en recién nacidos \\ Mexicanos sanos
}

\author{
Rocío L. Pedraza-Melchor ${ }^{1,2}$, Rodrigo Hernández-Benítez ${ }^{3 *}$, José Iglesias-Leboreiro ${ }^{1}$, \\ Désireé Vidaña-Pérez ${ }^{1}$, Isabel Bernardez-Zapata ${ }^{1}$, and Yogen Singh ${ }^{4}$ \\ ${ }^{1}$ Department of Neonatology, Hospital Español de México, Mexico City; ${ }^{2}$ Postgraduate Department, School of Medicine Universidad La Salle México, \\ Mexico City; ${ }^{3}$ Department of Pediatrics, Hospital Español de México, Mexico City, Mexico; ${ }^{4}$ Department of Neonatology, Cambridge University \\ Hospitals NHS Foundation Trust and University of Cambridge School of Clinical Medicine, Cambridge, United Kingdom
}

\begin{abstract}
Objective: Right ventricle (RV) function plays an important role during fetal and neonatal transitional circulation. Despite the published echocardiography guidelines in children including neonates, there is scare evidence on RV assessment using echocardiography in Mexican neonates. This study was aimed at assessing RV function and anatomical measures in healthy term newborns and defines normal values in this cohort of patients. Methods: A prospective study involving healthy term newborns in a single center were enrolled in the study to assess RV, all patients were recruited within 24-72 $h$ after birth. The right ventricular assessment was performed as per American Society of Echocardiography's guidelines. Results: Seventy healthy term newborns with a median gestational age of 38 (38.5 \pm 2.7$)$ weeks had RV function assessment and anatomical structures measures with a predefined ten echocardiographic parameters protocol. The mean values for: tricuspid valve diameter was $13 \mathrm{~mm} \pm 1.8$, basal diameter of the $R V 16.7 \mathrm{~mm} \pm 2$, RV length $27.8 \mathrm{~mm} \pm 2.2$, mid cavity diameter 14.3 $\mathrm{mm} \pm 1.7, \mathrm{RV}$-anteroinferior basal diameter $21.5 \mathrm{~mm} \pm 2.5$, tricuspid regurgitation gradient $13.3 \mathrm{mmHg} \pm 5.9$, tricuspid annular plane systolic excursion $8.7 \mathrm{~mm}$, right ventricular fractional area change (RVFAC) 4 chamber (\%) 40.6 \pm 7.5 , tricuspid $E / A 0.7 \pm 0.5$, myocardial velocities $(\mathrm{cm} / \mathrm{s}) E^{\prime} 8 \pm 2.7, A^{\prime} 9.6 \pm 2.4, S^{\prime} 6.9 \pm 1.2$, myocardial performance index $0.5 \pm 0.1$, RVFAC 3 chamber (\%) $37.8 \pm 15.8$, and pulmonary acceleration time mean value $58.8 \pm 14.9$. Flattening of interventricular septum was seen in $13 \%$ infants. Conclusions: This study describes echocardiographic parameters for anatomical structures and assessment of RV function in healthy term newborns during transitional circulation. We reported novel anatomical measures of the $R V$; this information can provide normal reference range values and be referenced while assessing RV function in normal and sick newborns during transitional circulation.
\end{abstract}

Key words: Neonates. Right ventricular function. Normal parameters.

\section{Resumen}

Objetivo: Realizar una valoración ecocardiográfica de parámetros anatómicos y funcionales del ventrículo derecho (VD) en recién nacidos de término (RNT) sanos durante el periodo transicional. Método: Estudio prospectivo en RNT sanos de

\section{Correspondence:}

*Rodrigo Hernández-Benítez

E-mail: roy210983@gmail.com
Available online: 02-07-2021

Arch Cardiol Mex. 2021;91(3):315-320 www.archivoscardiologia.com 1405-9940 / C 2020 Instituto Nacional de Cardiología Ignacio Chávez. Published by Permanyer. This is an open access article under the CC BY-NC-ND license (http://creativecommons.org/licenses/by-nc-nd/4.0/).

Date of reception: 11-02-2020

Date of acceptance: 05-11-2020

DOI: $10.24875 /$ ACM.20000063 
la Unidad de Cuidados Intensivos Neonatales del Hospital Español. Todos los pacientes fueron estudiados en las primeras 24-72 horas de vida, con base en las guías de la American Society of Echocardiography. Resultados: Se estudiaron 70 RNT sanos con una media de edad gestacional de 38 semanas de gestación ( $38.5 \pm 2.7$ ); en estos pacientes se obtuvieron 10 parámetros ecocardiográficos. El valor medio obtenido para la válvula tricúspide fue de $13 \pm 1.8 \mathrm{~mm}$, diámetro basal del VD $16.7 \pm 2 \mathrm{~mm}$, longitud $27.8 \pm 2.2 \mathrm{~mm}$, cavidad media del VD $14.3 \pm 1.7 \mathrm{~mm}$, diámetro basal anteroinferior $21.5 \pm 2.5 \mathrm{~mm}$, gradiente de insuficiencia tricuspídea $13.3 \pm 5.9 \mathrm{mmHg}$, tricuspid annular plane systolic excursion (TAPSE) $8.7 \mathrm{~mm}$, Fracción de acortamiento del VD (FAVD) 4 cámaras (\%) $40.6 \pm 7.5$, E/A tricuspídeo $0.7 \pm 0.5$, velocidades miocárdicas (cm/s) E' $8 \pm 2.7, A^{\prime} 9.6 \pm 2.4, S^{\prime} 6.9 \pm 1.2$, índice de rendimiento miocárdico $0.5 \pm 0.1$, FAVD 3 cámaras (\%) $37.8 \pm 15.8$, tiempo de aceleración pulmonar $58.8 \pm 14.9$. Conclusiones: Este estudio describe parámetros anatómicos y funcionales del VD en RNT sanos durante el periodo de transición. Se reportan valores de normalidad que pueden servir como referencia.

Palabras claves: Neonatos. Ventrículo derecho. Parámetros funcionales y anatómicos.

\section{Introduction}

In the fetus, the right ventricle $(\mathrm{RV})$ is the dominant chamber accounting for about $60 \%$ of total cardiac output and about $90 \%$ of the RV outflow volume is shunted from pulmonary artery to descending aorta through ductus arteriosus. Soon after birth, with aeration and expansion of lungs pulmonary vascular resistance (PVR) rapidly falls allowing increased pulmonary blood flow and reversal of shunt across ductus arteriosus. With increased pulmonary venous return leading to increased left atrial pressure foramen ovale closes soon and gradually ductus arteriosus closes in most term infants within first 24-48 $\mathrm{h}$. This established the neonatal circulation. However, PVR remains high during the $1^{\text {st }}$ few weeks of life and reached to nadir, equivalent to adults, at around 6 weeks of age. During this time, there is a gradual change in dominance of the ventricles. RV, which is the predominant ventricle during fetal period, remains bigger than LV during transitional circulation and gradually LV dominance takes over ${ }^{1,2}$.

There is evidence that RV plays a significant role during transition circulation. Conventionally, functional assessment just involved qualitative assessment based on a visual inspection, "eyeballing," but in recent years the growing interest among neonatologists and cardiologists to establish standard echocardiographic parameters to assess RV function quantitatively lead The American Society of Echocardiography (ASE) in 2010 to publish guidelines for the assessment of the right heart in children. Despite this, in Mexico there are no studies addressing this subject ${ }^{3,4}$.

The main goal of this study was to perform a simple ten parameter echocardiographic protocol to analyze RV function and obtain anatomical measurements in newborn babies during the first $72 \mathrm{~h}$ after birth, establishing normal reference values for Mexican neonates.

\section{Methods}

\section{Study design}

For this prospective study, 70 healthy term newborns were recruited between June and December 2018 from the neonatal Unit at Hospital Español de México, Mexico City. The health records of all newborns who received routine postnatal care were screened.

On the basis of ASE guidelines, we developed a comprehensive RV functional protocol for term babies (gestational age, 37-42 weeks) and after a well-informed written consent all eligible newborns had echocardiographic assessment as per protocol between 24 and $72 \mathrm{~h}$ after birth.

\section{Inclusion criteria}

The following criteria were term healthy neonates, normal APGAR score, and no history of any respiratory symptom. All exams were examined in a resting state without prior sedation and were allowed comfort bottle feeding during the assessment.

\section{Exclusion criteria}

The following criteria were all the known factors which potentially can impact transitional circulation and RV function such as: maternal diseases (diabetes mellitus, chorioamnionitis, and placental dysfunction), newborns with confirmed perinatal asphyxia or need for active resuscitation at birth, PDA $>1.5 \mathrm{~mm}$ or symptomatic, suspected sepsis or any known medical illness, presence of any congenital or genetic malformation, suspected or confirmed pulmonary hypertension or need for inotropic, and chronotropic drugs. 
The study was approved by the ethics committee at Hospital Español de México.

\section{Echocardiographic methods}

A simple ten parameter echocardiographic protocol was applied in newborn babies during the first $72 \mathrm{~h}$ after birth. The measurements were derived using multiple views and modes of echocardiography as agreed in the protocol. An echocardiogram was performed using an Acuson X150 scanner with an 8-MHz transducer (Siemens Medical Solutions USA) with the use of electrocardiogram electrodes in all cases. All the studies were performed and analyzed by a single pediatric cardiologist and echocardiographist; the images were digitally store for further analysis.

\section{RV dimensions}

From an RV four-chamber (RV-4C) view, the tricuspid valve (TV) annular diameter was defined as a straight line joining the hinge points of the anterior and septal valve leaflets. The basal diameter was measured at the basal third of the RV cavity as the maximal distance from the RV lateral wall to the septum while maintaining a parallel orientation to the TV annulus (TVA). A straight line joining the midpoint of the TVA to the RV apex constituted the RV length. The mid cavity diameter was defined by a straight distance between the RV lateral wall and the septum running parallel to the TVA but passing through the mid-point of RV length. In addition, with the aim of quantifying right ventricular anteroinferior dimension, the right ventricular inflow tract view was obtained by angling the sound beam toward the patient's right hip. This was measured as the maximal diameter at the basal third of the RV cavity from its anterior to inferior walls while maintaining a parallel orientation with the TVA. All dimensions were measured in end-diastole.

\section{Fractional area change (FAC)}

Right ventricular fractional area change (RVFAC) represents a surrogate measurement of RV ejection fraction and is expressed as a percentage change in the $\mathrm{RV}$ chamber area from end-diastole to end-systole, the RVFAC is calculated as follow:

$$
\begin{aligned}
& \text { End - diastolic area }\left(\mathrm{cm}^{2}\right)- \\
& \frac{\text { end systolic area }\left(\mathrm{cm}^{2}\right)}{\text { End diastolic area }\left(\mathrm{cm}^{2}\right)} \times 100
\end{aligned}
$$

\section{Tricuspid annular plane systolic excursion (TAPSE)}

TAPSE was measured by two-dimensional echocardiograph-guided M-mode recordings from the apical $4 \mathrm{C}$ view with the cursor place at free wall of the tricuspid annulus as parallel as possible.

\section{TV inflow}

TV inflow was assessed by placing a pulsed-wave (PW) sample gate of $2 \mathrm{~mm}$ at the tip of the TV leaflets during diastole with the Doppler beam parallel to the inflow as visualized using color Doppler echocardiography. Early (E) and late (A) TV inflow velocities and their ratio $(E / A)$ were measured.

We also measured the tricuspid regurgitation (TR) expressed in $\mathrm{mmHg}$ by placing a continuous-wave (CW) Doppler $2 \mathrm{~mm}$ below the tip of the TV leaflets during diastole.

\section{Myocardial velocities}

Pulsed tissue Doppler imaging (TDI) of the tricuspid annulus was obtained by placing a PW Doppler just below the lateral tricuspid annulus. With this we could measure: Peak systolic ( $\left.S^{\prime}\right)$, early diastolic $\left(E^{\prime}\right)$, and late diastolic $\left(A^{\prime}\right)$ velocities.

\section{$R V$ myocardial performance index (MPI)}

RV MPI or Tei index were measure by the time intervals: isovolumic contraction time (ICT), isovolumic relaxation time (IRT), and right ventricular ejection time (RVET). TDI and MPI were calculated by the use of the following formula.

$$
\mathrm{MPI}=[\mathrm{ICT}(\mathrm{ms})+\mathrm{IRV} \mathrm{ms})] / \mathrm{RVET}(\mathrm{ms})
$$

\section{Pulmonary artery acceleration time (PAAT)}

This parameter was measured from PW Doppler of the main pulmonary artery from the parasternal long-axis view of the RV outflow tract, we measured the beginning of pulmonary systolic flow till the peak of systolic ejection, and this parameter was expressed in milliseconds.

\section{Interventricular septal motion at end- systole (IVSs)}

IVSs were assessed by visual inspection of the interventricular septum from a $2 \mathrm{D}$ short-axis view acquired 
at the level of the mitral valve. IVSs was considered "flat" if there was a complete absence of concavity toward the left ventricle.

\section{Results}

Characteristics of patients and results of anatomical and functional parameters are summarized in tables 1 and 2 , figures 1-6. A total of 70 full-term neonates fulfilled the inclusion criteria; based on weight we established anatomical parameters for basal, anteroinferior basal, mid cavity diameter, and length.

All values for TAPSE and TV measurements were in normal values based on Z score ${ }^{5,6}$, myocardial velocities on the peak systolic ( $\left.\mathrm{s}^{\prime}\right)$, early diastolic $\left(\mathrm{e}^{\prime}\right)$, and late diastolic $\left(a^{\prime}\right)$ contraction velocities were $8( \pm 2.7)$, $9.6( \pm 2.4)$, and $6.9( \pm 1.2)$, respectively, MPI index mean was $0.5( \pm 0.1)$. Finally, $13 \%$ neonates had flattening of interventricular septum and the mean PAAT was $58.8 \mathrm{~ms} \pm 14.9$.

\section{Discussion}

The RV function is recognized as a critical prognostic factor in the management of cardiopulmonary disorders and congenital heart defects in neonates 7,8 . This study establishes anatomic and functional parameters in Mexican healthy term infants during the transitional period.

The mean TAPSE value reported correlates with the study by Koestenberger et al. reporting a mean value of $8.6 \mathrm{~mm}$ for neonates around 38 weeks of gestation. This parameter was one with the lowest variation $( \pm 1.1)$ and one of the most simple and reproducible echocardiographic parameters for RV function assessment ${ }^{5}$.

Mean RVFAC is similar to that reported by Levy et al. of $33 \% \pm 5$ in 25 term babies. However, in the same study, the FAVD 4C was higher in patients with a weight $>2.5 \mathrm{~kg}$, reaching values above the $35 \%$ similar to our study involving healthy infants with good weight and height ${ }^{9}$.

Alp et al. reported values for MPI and myocardial velocities performed in neonates in the $1^{\text {st }}$ day after birth in 50 term infants, values for tricuspid EA radio was 0.85 (vs. 0.7 in our study), $E^{\prime} 6.4 \mathrm{~cm} / \mathrm{s} \pm 1.2, A^{\prime}$ $8.7 \mathrm{~cm} / \mathrm{s} \pm 1.3, S^{\prime} 6.5 \mathrm{~cm} / \mathrm{s} \pm 1.4$ and MPI of RV of 0.46 \pm 0.02 (vs. $8 \mathrm{~cm} / \mathrm{s} \pm 2.7,9.6 \mathrm{~cm} / \mathrm{s} \pm 2.4,6.9 \mathrm{~cm} / \mathrm{s} \pm 1.2$, and $0.5 \pm 0.1$, respectively, in our study), their study group was very similar to ours with a mean birth weight and height of $3085 \pm 256 \mathrm{~g}$ and $46.7 \pm 3.4 \mathrm{~cm}$, respectively ${ }^{10}$.
Table 1. Characteristics of the population mean and standard deviation $(n=70)$

\begin{tabular}{|l|c|}
\hline Characteristics & Mean or proportion \pm SD \\
\hline Girls (\%) & 55 \\
\hline Boys (\%) & 45 \\
\hline Gestation weeks & $38.5 \pm 2.7$ \\
\hline Weight (kg) & $3.1 \pm 0.4$ \\
\hline Height (cm) & $48.7 \pm 1.5$ \\
\hline
\end{tabular}

Table 2. Summary of echocardiographic parameters for right ventricular assessment in 70 patients. Data are expressed as mean \pm SD

\begin{tabular}{|l|c|}
\hline Parameters & Mean \pm SD \\
\hline TV diameter (mm) & $13 \pm 1.8$ \\
\hline Basal diameter (mm) & $16.7 \pm 2$ \\
\hline RV length (mm) & $27.8 \pm 2.2$ \\
\hline Mid cavity diameter (mm) & $14.3 \pm 1.7$ \\
\hline RV-AIBD (mm) & $21.5 \pm 2.5$ \\
\hline Tricuspid regurgitation (mmHg) & $13.3 \pm 5.9$ \\
\hline FAVD 3C (\%) & $37.8 \pm 15.8$ \\
\hline FAVD 4C (\%) & $40.6 \pm 7.5$ \\
\hline Tricuspid E/A ratio & $0.7 \pm 0.5$ \\
\hline MPI index & $0.5 \pm 0.1$ \\
\hline Pulmonary artery acceleration time (ms) & $58.8 \pm 14.9$ \\
\hline
\end{tabular}

TV: tricuspid valve, RV: right ventricle, RV-AIBD: right ventricular anteroinferior basal diameter, FAVD: fracción de acortamiento del VD, MPI: myocardial performance index.

The use of Doppler measurement of PAAT is commonly used for the evaluation of PAP is well-established in adults and values $<100$ ms showed a linear inverse relationship between the PAAT and mean PAP in adults. A shorter PAAT suggests elevated pulmonary artery pressure (PAP) and PVR. From a study involving 113 neonates, Koestenberger et al. reported a mean PAAT value of $81 \mathrm{~ms}$ (range 53-104 ms) when mean heart rate was 131 beats per minute, he concluded PAAT value has an inverse relationship with the heart rate. In our study, we established a mean value for PAAT of $58.8 \pm$ $14.9 \mathrm{~ms}$, unfortunately we could not establish a correlation between the heart rate and the value of PAAT ${ }^{11,12}$.

The novel of this study was established reference values based on weight for basal diameter, RV length, mid cavity, and RV-AIB diameters, actually does not 


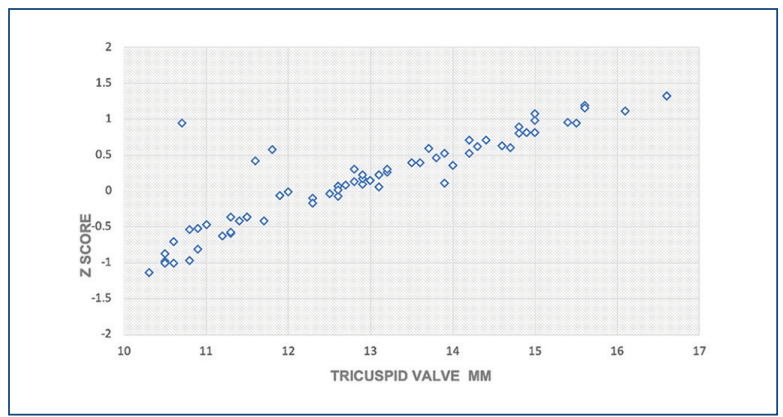

Figure 1. Tricuspid valve measurement and Z score.

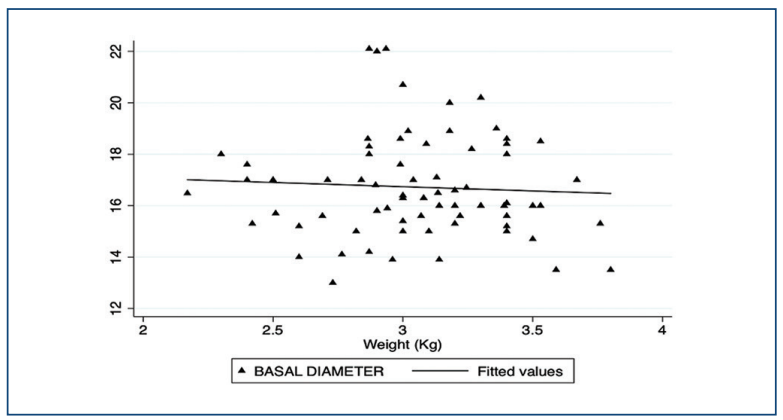

Figure 2. Weight versus observed value of basal RV diameter in $\mathrm{mm}$ (right ventricle). The mean is indicated by a solid black line.

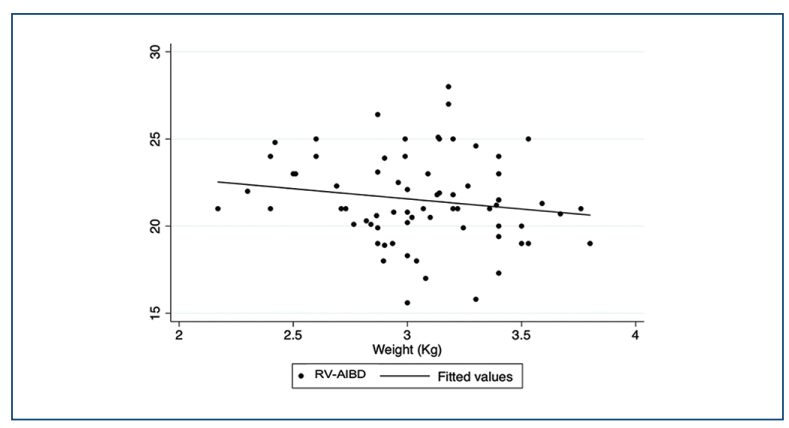

Figure 3. Weight versus observed value of right ventricular anteroinferior basal diameter in $\mathrm{mm}$. The mean is indicated by a solid black line.

exist z score for this parameter so it is important to continue with this kind of studies to establish normal values in neonates.

Finally, in our cohort nine patients (13\%) had mild flattening of interventricular septum, this group did not have any evidence of pulmonary hypertension, the mean value of TR was $18.7 \mathrm{mmHg}(8-25 \mathrm{mmHg})$ and the mean value for PAAT was $56.8 \mathrm{~ms}(45-80 \mathrm{~ms})$, this

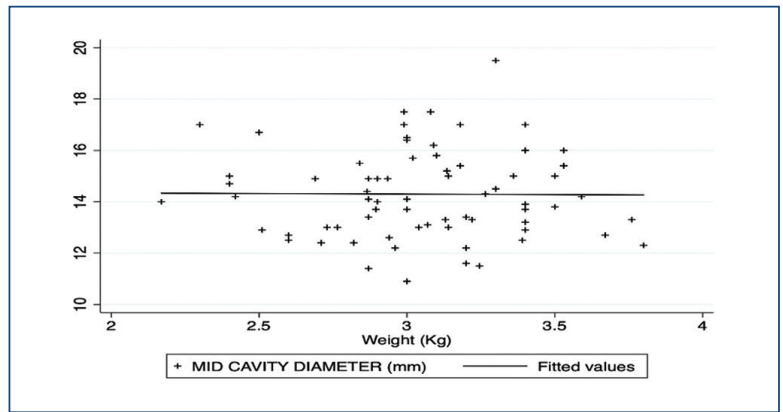

Figure 4. Weight versus observed value of mid cavity diameter measurement in $\mathrm{mm}$. The mean is indicated by a solid black line.

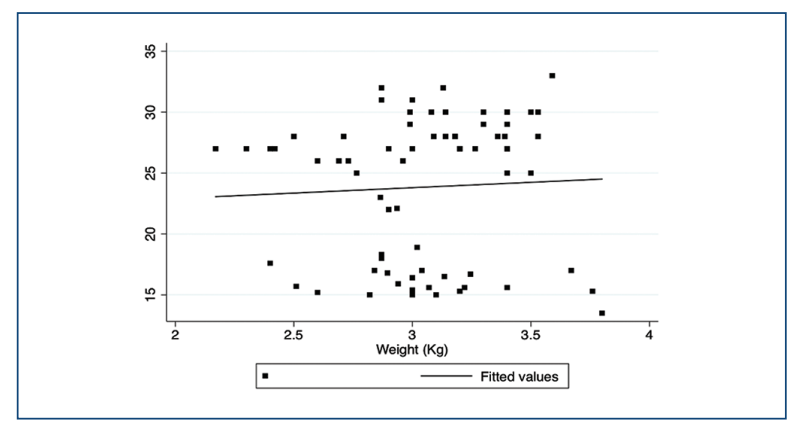

Figure 5. Weight versus observed value of right ventricular length measurement in $\mathrm{mm}$. The mean is indicated by a solid black line.

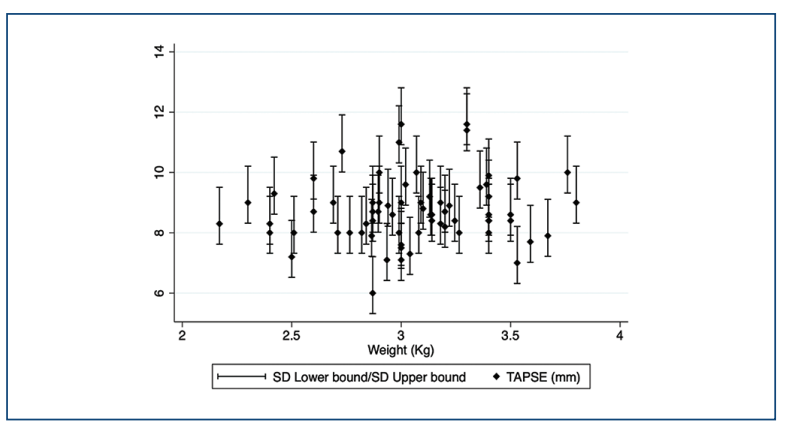

Figure 6. Mean tricuspid annular plane excursion values with error bars of \pm 2 SD of the mean values for weight.

neonates were follow until their hospital discharge without any medical condition or complication and did not have readmission.

\section{Study strengths and limitations}

This study report for first time RV anatomical and functional parameters in Mexican neonates, for novel 
we could establish in base weight normal anatomical parameters for RV. Although the number of patients is small (70), as compared to previously reported studies this is $2^{\text {nd }}$ largest study establishing normal reference values for RV function assessment in neonates.

The main limitation of this study was that we could not have interobserver variability due to the fact that only one pediatric cardiologist performed and analyzed the images. On the other hand, to our strength, the analysis was performed by said cardiologist who is highly trained and experienced in functional echocardiography. This study was not designed to measure cardiac output, assess left ventricle function, or measure size of foramen ovale. Finally, this study protocol did not include speckle-tracking, strain assessment and 3D imaging as a result of a lack of resources. Speckle tracking and 3D -imaging techniques seem promising to assess the RV function but till date they remain primarily research tools and need special expertise, currently available only in few centers around the world. Hence, we believe our protocol is simple and feasible to apply in clinical practice across the majority of neonatal and cardiac intensive care units.

\section{Conclusions}

The assessment of RV with echocardiogram is of utmost importance to the neonatologists and pediatric cardiologists providing care to sick neonates. To the best of our knowledge, this is the first study with important anatomical measurements and functional information in Mexican healthy term newborns. We recommend performing further prospective studies using similar protocols in preterm and sick neonates with underlying pathologies.

\section{Funding}

This research did not receive any specific grant from funding agencies in the public, commercial, or not-forprofit sectors.

\section{Conflicts of interest}

No conflicts of interest.

\section{Ethical disclosures}

Protection of human and animal subjects. The authors declare that no experiments were performed on humans or animals for this study.

Confidentiality of data. The authors declare that they have followed the protocols of their work center on the publication of patient data.

Right to privacy and informed consent. The authors declare that no patient data appear in this article.

\section{References}

1. Singh $\mathrm{Y}$, Tissot $\mathrm{C}$. Echocardiographic evaluation of transitional circulation for the neonatologists. Front Pediatr. 2018:6:140.

2. Greyson $\mathrm{CR}$. Ventrículo derecho y circulación pulmonar: conceptos básicos. Rev Esp Cardiol. 2010;63:81-95.

3. Segovia J, Bermejo J, Alfonso F, Heras M. Corazón derecho y circulación pulmonar: una circulación menor? Rev Española Cardiol. 2010;63:77-80.

4. Lopez L, Colan SD, Frommelt PC, Ensing GJ, Kendall K, Younoszai AK, et al. Recommendations for quantification methods during the performance of a pediatric echocardiogram: a report from the pediatric measurements writing group of the American society of echocardiography pediatric and congenital heart disease council. J Am Soc Echocardiogr. 2010;23:465-95.

5. Koestenberger M, Ravekes W, Everett AD, Stueger HP, Heinzl B, Gamillscheg $A$, et al. Right ventricular function in infants, children and adolescents: reference values of the tricuspid annular plane systolic excursion (TAPSE) in 640 healthy patients and calculation of $z$ score values. J Am Soc Echocardiogr. 2009;22:715-9.

6. Pettersen MD, Du W, Skeens ME, Humes RA. Regression equations for calculation of $z$ scores of cardiac structures in a large cohort of healthy infants, children, and adolescents: an echocardiographic study. J Am Soc Echocardiogr. 2008;21:922-34.

7. Warnes CA. Adult congenital heart disease. J Am Coll Cardiol. 2009;54:1903-10.

8. Haddad F, Hunt SA, Rosenthal DN, Murphy DJ. Right ventricular function in cardiovascular disease, Part I. Circulation. 2008;117:1436-48.

9. Levy PT, Dioneda B, Holland MR, Sekarski TJ, Lee CK, Mathur A, et al. Right ventricular function in preterm and term neonates: reference values for right ventricle areas and fractional area of change. J Am Soc Echocardiogr. 2015;28:559-69.

10. Alp H, Karaarslan S, Baysal T, Çimen D, Örs R, Oran B. Normal values of left and right ventricular function measured by Mumode, pulsed doppler and Doppler tissue imaging in healthy term neonates during a 10year period. Early Hum Dev. 2012;88:853-9.

11. Koestenberger M, Avian A, Grangl G, Burmas A, Kurath-Koller S, Hansmann G. Right ventricular outflow tract velocity time integral (RVOT VTI) and tricuspid regurgitation velocity/RVOT VTI ratio in pediatric pulmonary hypertension. Int J Cardiol. 2016;212:274-6.

12. Koestenberger M, Grangl G, Avian A, Gamillscheg A, Grillitsch M, Cvirn G, et al. Normal reference values and $z$ scores of the pulmonary artery acceleration time in children and its importance for the assessment of pulmonary hypertension. Circ Cardiovasc Imaging. 2017;10:e005336. 